\title{
A nação ao redor: da formação enquanto totalidade a interpretações parciais do Brasil
}

Renato Cordeiro Gomes ${ }^{1}$

\begin{abstract}
The title of this essay is inspired by Neighboring Sounds (2012), a film by Kleber Mendonça Filho, which is emblematic of a contemporary way of interpreting Brazil. Mendonça Filho's film is the starting point and the goal of these reflections, which probe the limits of the strategy to interpret the Brazilian nation as a totality, conditioned by the epistemology of "formation". The displacement of this tradition leads to the consideration of clippings of daily urban life, both in literature and mass media culture of the 2000s, a time marked by the appearance of new editions of the classic and canonical social sciences texts that had programmatically assumed the task of interpreting the Nation throughout the $20^{\text {th }}$ century. The essay inquires the extent to which, in these partial visions, the nation is no longer the center of a system of signification, even though it persists as residual in relation to the legacy of the tradition of the interpreters of Brazil, such as presented in Neighboring Sounds script.
\end{abstract}

Keywords: Brazil interpreters; formation; totality; residues; partial interpretations.

Resumo: O título deste ensaio é motivado pelo filme O Som ao redor (2012), de Kleber Mendonça Filho, emblemático de um modo contemporâneo de interpretar o Brasil. É ponto de partida e de chegada destas reflexões que buscam colocar em questão o ultrapassamento da estratégia romântico-modernista de interpretar a nação enquanto totalidade, pautada pela epistemologia da "formação". O deslocamento dessa tradição leva a considerar recortes do cotidiano urbano, na literatura e na cultura midiática dos anos 2000, quando, por outro lado, se reeditam as obras clássicas e canônicas das Ciências Sociais, que programaticamente se impunham a tarefa de interpretar a Nação, ao correr do século XX. Indaga-se se, nessas visões parciais, a Nação deixa de ser o centro de um sistema de significação, embora persista enquanto residual (na acepção de Raymond Williams) em relação à herança da tradição dos intérpretes do Brasil, como é roteirizado em Som ao redor. Palavras-chave: Intérpretes do Brasil; formação; totalidade; resíduos; interpretações parciais.

Todos nós, cidadãos brasileiros, somos intérpretes do Brasil, com nossa visão de mundo e idiossincrasias familiares, ideológicas e partidárias. São tarefas suplementares na vida cotidiana.

Silviano Santiago, Mário, Oswald e Carlos: intérpretes do Brasil

1 Professor Associado da Pontifícia Universidade Católica do Rio de Janeiro. 


\section{Conexão Letras}

A morte de Ariano Suassuna, em 23/07/2014, trouxe, no bojo dos obituários e das matérias encomiásticas na imprensa, na televisão (entrevistas e imagens de arquivo), nas redes sociais, a exaltação - quase mitificação - desse escritor nordestino como intérprete do Brasil, comprometido na busca de autenticidade da nossa cultura, no esforço de produzir uma arte brasileira erudita a partir de raízes populares, batendo-se contra a globalização da cultura. Atitude não só comprovada pela sua obra, bem como pelas aulas-espetáculo que realizou pelo País, em que analisava a cultura brasileira, exaltando o que considerava autêntico: as origens ibéricas, a tradição dos violeiros, dos cantadores, das rabecas, dos cordéis, e, ainda, pela sua atuação na Secretaria de Cultura de Pernambuco (1994-1998). Disse ele, numa de suas famosas frases que circula pela Internet: "O Brasil tem uma unidade em sua diversidade. A gente respeita a cultura gaúcha, nordestina, amazônica. O que é ruim é este achatamento cosmopolita. Você liga a televisão e não consegue distinguir se um cantor é alemão, brasileiro ou americano, porque todos cantam e se vestem do mesmo jeito". (SUASSUNA, 2014)

Em matéria do jornal JáEditora, Enio Squeff (2014) abre seu artigo - “Ariano Suassuna e os intérpretes do Brasil" - com o parágrafo: "É possível que não exista um país com tantos intérpretes quanto o Brasil. Talvez o tamanho do país justifique tantos esforços genéticos”, introduzindo/entronizando a figura do escritor em sua cruzada de "louvar o Brasil", ao lado das críticas que muitos consideravam xenófobas. Lembrem-se as investidas contra o maracatu eletrônico e movimento de música Mangue-beat, ou declarações, como a que fez em entrevista ao Jornal do Brasil, em 7/12/1997: "Sou a favor da internacionalização da cultura, mas não acabando as peculiaridades locais e nacionais”. E ainda:

As pessoas dizem que sou contra a cultura americana. Melville é um gênio e Moby Dick uma das maiores obras-primas da literatura universal de todos os tempos. Do que não gosto é dessa cultura massificada que querem nos impor como modelo, então dizem que sou contra a cultura americana pelo fato de ser contra Michael Jackson ou Madonna. Os próprios americanos que têm juízo também são. (SUASSUNA, 2014)

O caso Suassuna é emblemático de uma cultura "empenhada", desde a independência política, em construir a identidade cultural da Nação, preocupação de escritores, poetas, cientistas sociais, cineastas etc, avançando por todo o século XX, quando era programático "descobrir o Brasil", que se associava à idéia de "formação". Talvez não seja imotivada, numa visão retrospectiva, do ponto de vista contemporâneo, balizar o século com a publicação, em 1900, do, hoje, muito falado e pouco lido Por que me ufano de meu país, do conde Affonso Celso, e com a coletânea Intérpretes do Brasil, organizada por Silviano Santiago, em 2000.

Exito editorial, Por que me ufano do meu país ${ }^{2}$ e, mais especificamente, a palavra ufanismo passaram a denotar o patriotismo acrítico, ingênuo, incondicional, como sublinha José Murilo de Carvalho, no artigo "500 anos de ilusão" (1999). Motivado de certa forma pelos quatrocentos anos do descobrimento do Brasil, traz uma epígrafe em inglês - "Right or wrong, my country" - e é dedicado aos filhos do autor, como história de prazer, proveito e exemplo, e conselhos, que, em seu aspecto pedagógico, pretende tornar-se útil, enquanto

2 Todas as citações deste livro, datado sintomaticamente de Petrópolis, 8 de setembro de 1900, aparecem aqui entre aspas, sem a indicação de páginas, por uma questão de estilo do pesquisador, que incorpora as expressões do conde Affonso Celso ao texto analítico. Remetem à quarta edição (Paris: Garnier, s. d.), que pode ser consultada na Biblioteca Brasiliana Guita e José Mindlin, já digitalizada pela USP: http://www.brasiliana. usp.br/bbd/bitstream/handle/1918/02173000/021730_COMPLETO.pdf. Último acesso, 03/05/2014. 
missão de um pai que passa a experiência do mais velho para as novas gerações - uma herança, portanto. Nos ensinamentos, avulta-se o patriotismo, em favor da causa da Pátria, mediada pelo afeto, que exige sacrifícios, até da vida. O entusiasmo, próprio da juventude, levado pelo emocional, deve ser minimizado, com o peso dos fundamentos do culto à pátria, que vem dos argumentos e dos fatos. Os acertos demonstrados são resultados da experiência e do estudo, necessários para "engrandecer o maior culto pelo Brasil", projetando a "nobre ufania", o que faz Affonso Celso, ao enumerar os motivos da superioridade do Brasil (que nada tem do complexo de vira-lata, como disse Nelson Rodrigues): "o Brasil é um mundo", um todo homogêneo que resume a superfície do planeta ("a grandeza física": "bastava esse predicado, se não houvesse outros"), a terra fértil ("em se plantando, tudo dá") ${ }^{3}$ - a flora exuberante, a população ("negros, brancos, peles-vermelhas, mestiços vivem aqui em abundância e paz": "Brasil, um conjunto solidário", ${ }^{4}$ a beleza ("a realidade tem o que a ardente imaginação possa fantasiar" ), a natureza (floresta: "conjunto sublime, reunião de todas as artes"); a riqueza, que o autor expressa pela fertilidade da terra, celeiro do mundo; o El-Dorado. ${ }^{5}$

Esses traços, aqui sintetizados, convergem para o tópico da distribuição da riqueza, expresso com palavras hiperbólicas: "a mais larga acessibilidade a tudo, no meio de condições sociais únicas, sem distinção e divergência de classes, em perfeita comunicação e homogeneidade da população", o que aparece associado à variedade e amenidades do clima, à ausência de calamidades, à excelência dos elementos que entraram na formação do tipo nacional, a exemplo dos traços sublimes dos índios e o papel dos negros ("contribuíram com tantos serviços para que no Brasil jamais houvesse preconceito de cor"). Tais traços harmonizam-se nos nobres predicados do caráter nacional.

Esses traços que constituem os onze motivos para a superioridade do nosso País em relação aos outros, engendram "a nobre ufania" (a expressão é do livro), "uma utopia adocicada" (a expressão é de Luiz Camillo Osório, 2011, p. 63), que reedita, com um discurso valorativo e descritivo, por meio de uma retórica de exaltação, o mito do Brasil como paraíso terreal. ${ }^{6}$ Esse motivo de longa duração, que vem da carta de Caminha e passa pelos Diálogos das grandezas do Brasil, atrela-se ao nacionalismo e dá continuidade (tradição) ao ufanismo (o livro do Conde contribuiu para a popularização do termo), explorado, por exemplo, pelos românticos (ver a "Canção do exílio", de Gonçalves Dias), estendendo-se,

3 A frase clichê, repetida pelo senso comum ou pelos discursos patrioteiros, às vezes de um nacionalismo ingênuo, será satirizada pela visão crítica no Triste fim de Policarpo Quaresma (1911), de Lima Barreto (BARRETO, 2013), em relação ao fracasso de seu empreendimento agrícola no sítio do Sossego. Seria rentável articular essa visão ufanista, que remete também à Carta de Pero Vaz de Caminha, com a brasiliana da biblioteca de Policarpo. Um fato biográfico curioso: o conde Affonso Celso era padrinho de Lima Barreto, que não incluiu o livro na biblioteca do personagem.

4 Essas tiradas ufanistas remetem à falácia da democracia racial do Brasil.

5 Os filhos do autor, a quem dedica o livro, bem como os filhos do Brasil, não são filhos da dor, como Moacir (de Iracema, de Alencar, de 1865), nem tampouco órfãos do Eldorado, como no romance homônimo de Milton Hatoum, de 2008. Um exercício bastante rentável seria rastrear na tradição da ficção brasileira o tema da orfandade (os órfãos da Nação), que também é recorrente no cinema brasileiro, a exemplo dos filmes de Walter Salles Jr, ou ainda associá-lo ao tema da esterilidade, da não descendência (ver, por exemplo, Memórias póstumas de Brás Cubas, de Machado de Assis, Vida e morte de M. J. Gonzaga de Sá, de Lima Barreto, Fogo morto, de José Lins do Rego, Ópera dos mortos, de Autran Dourado, e Heranças, de Silviano Santiago), romances que revelam modos de interpretar o Brasil.

6 Neste sentido, é útil a consulta a Visão do Paraíso: os motivos edênicos no descobrimento e colonização do Brasil, de Sérgio Buarque de Holanda (2010), em que o historiador trabalha os lugares discursivos para inventariar as miragens do Éden que acompanharam as narrativas do descobrimento e da colonização, acionando um imaginário edênico que suplantava a percepção da realidade. 
a partir dos anos 1930, aos sambas-enredo das escolas de samba, aos sambas-exaltação, como o emblemático "Aquarela do Brasil”, de Ari Barroso, considerado o segundo hino nacional, ou na propaganda e outros produtos culturais das ditaduras do Estado Novo e do regime civil-militar de 1964.

Se um texto ufanista abre as interpretações do Brasil, em 1900, o século XX se fecha e aponta para o século XXI, fazendo uma espécie de balanço do que foi ler o Brasil ao correr do século em que se agudizaram os modos de entendê-lo. Trata-se, justamente, da reunião dos textos hoje clássicos e canônicos de cientistas sociais, que interpretam o País, nos mais diversos temas. Sublinhe-se ser esta a única coletânea que inclui um romance Vidas secas, de Graciliano Ramos - entre aqueles intérpretes. Com curadoria de Silviano Santiago, os livros selecionados constituem os três volumes de Intérpretes do Brasil, editado pela Nova Aguilar, em 2000, um projeto cultural patrocinado pelo Ministério das Relações Exteriores e pelo Ministério da Cultura. Tal iniciativa oficial tinha como motivação as comemorações dos quinhentos anos da descoberta do Brasil, embora a este propósito a introdução do organizador não faça menção.

Ao escolher os textos, assumindo todos os riscos e esquecimentos que qualquer seleção implica, atesta o organizador sobre os critérios adotados: "São estes os melhores ensaios escritos por brasileiros sobre o Brasil depois da Independência do país (...). Os dez ensaios e um romance foram eleitos a partir de um "princípio organizador que desse a dimensão da força intelectual que desenvolvemos, geração após geração, para refletir sobre o próprio país". E enumera os pares de conceitos que o guiaram: "O feito, o que está sendo feito e o que deverá ser feito. Pensamento e ação. Injustiças e verdades. Fracassos e conquistas. Reflexão e autoconhecimento. O particular e o universal. Crítica e autocrítica. Idéias e governabilidade. Ideologias e fanatismo" (SANTIAGO, 2000, p. 22). Nesta "Introdução" e em outros textos ficcionais e ensaísticos de sua autoria, o próprio Silviano revela-se como intérprete do Brasil, como expõe Eneida Leal Cunha no ensaio "Do crânio da onça jabuti faz seu escudo: Silviano Santiago como intérprete do Brasil” (2011), apresentado no colóquio "Intérpretes do Brasil", organizado por Luiz Fernando Valente, no Congresso da APSA, na Brown University, em 2010.

Como esclarece Silviano, o projeto se concretizou "numa coletânea de textos que mostra como é que pensamos e continuamos a pensar o Brasil”". Os ensaios são suplementados por introduções escritas por intelectuais, pesquisadores e professores de renome, oferecendo "interpretações de interpretações". Começa com o clássico O Abolicionismo, de Joaquim Nabuco, segue com Os Sertões, de Euclides da Cunha; A América Latina, de Manuel Bonfim; o primeiro volume de Populações Meridionais do Brasil, de Oliveira Viana; Vida e Morte do Bandeirante, de Alcântara Machado; Retrato do Brasil, de Paulo Prado; Raízes do Brasil, de Sérgio Buarque de Holanda; Formação do Brasil Contemporâneo, de Caio Prado Júnior; e A Revolução Burguesa no Brasil, de Florestan Fernandes. Além dos três clássicos de Gilberto Freire: Casa-Grande \& Senzala, Sobrados e Mocambos e Ordem e Progresso (ter três livros do sociólogo pernambucano foi exigência de seus herdeiros). A seleção se completa com o único romance escolhido por Santiago: Vidas Secas, de Graciliano Ramos, sinalizando com este desvio em relação às Ciências Sociais que a literatura também é um dos modos de pensar e interpretar o Brasil. Neste sentido, podem ser lembradas, por exemplo, as referências a José de Alencar, Machado de Assis e Mário de Andrade, bem como o ensaio "Mário, Oswald e Carlos, intérpretes do Brasil" (2005, p. 5-17), em que, para indagar se os três modernistas poderiam ser considerados intérpretes do Brasil, Santiago se vale de material considerado menor (cartas, artigos e entrevistas publicados em jornal), a fim de mostrar como a procura cotidiana duma interpretação para 
o Brasil fez parte da formação de cada um deles. A interpretação do Brasil a que chegaram foi o pré-requisito para que pudessem escrever as obras que escreveram - conclui ele.

A maioria desses pensadores, ligada ao projeto modernista, tem a preocupação de "descobrir" (ver a abertura de Pau-brasil, de Oswald de Andrade: "por ocasião da descoberta do Brasil" - 1924, data da famosa viagem da caravana dos modernistas paulista e Blaise Cendras a Minas Gerais) e interpretar o Brasil como uma totalidade, mesmo considerando a diversidade, a multiplicidade. É um motivo recorrente nesses textos a idéia de formação, a grande narrativa legada pela Razão iluminista. Formação que implica também a idéia de invenção, de construção: "fazer uma nação e uma literatura são processos simultâneos", portanto, na base da semelhança, por outro lado, hoje, "a diferença cultural intervém para transformar o cenário da articulação, reorientando o conhecimento através da perspectiva significante do 'outro' que resiste á totalização", como lemos em Nações literárias, de Wander Melo Miranda (2010, p.21-22)

O paradigma formação, porém, é dado, hoje, como agônico, como formula Silvano Santiago no pequeno ensaio "Formação e inserção", publicado no caderno Sabático, do Estado de São Paulo, em 26/05/2012:

Ao se elevar à condição de paradigma, "formação" funda e estrutura no século XX brasileiro os múltiplos saberes confessionais, artísticos e científicos que compartilham - a despeito de suas especificidades e apesar de versar sobre objetos diferentes - determinadas formas ou características gerais do nosso ser e estar em desenvolvimento. [...] O discurso de formação está a perder a condição de prioritário. A exaustão deriva de transformações significativas na definição de prioridades nacionais, das prioridades materiais, no novo milênio que exigem outro feixe de discursos afins e complementares, que constituirão novo paradigma. [...] Produzem-se novas visões e versões do cidadão brasileiro e da nossa sociedade. [...] Hoje, a produção discursiva deve fundar e disseminar novo paradigma - a que ouso nomear como o da "inserção". Faz-se urgente dar uma posição à "inserção da linguagem-Brasil em contexto universal" para retomar palavras premonitórias de Hélio Oiticica no texto "Brasil diarréia” (SANTIAGO, 2013, p. 259-262).

Por outro lado, é sintomático o alto nível de deslocamento e de estranhamento do sujeito-escritor no discurso, como destaca Eneida Maria de Souza, ao estudar o romance O filho da mãe (2009), escrito por Bernardo Carvalho para o projeto Amores Expressos, ${ }^{7}$ confirmando a saída romanesca para outros lugares, como se dá com os relatos desse projeto, encampado pela Companhia das Letras, e também com Mongólia (2003), do próprio Carvalho. Acrescenta a ensaísta mineira: “O deslocamento literal e metafórico dos parâmetros modernos nacionalistas responde hoje por uma ficção politicamente engajada nos dramas sociais, situados aqui e além dos territórios e dos interesses locais" (SOUZA, 2011, p. 251). Ao analisar os malabarismos do enredo, a pesquisadora observa que "o livro denuncia as ruínas do ambiente artístico, literário e político da cidade de para encenar as contradições e os problemas existenciais causados pelos problemas multiculturais" (p. 253). E no mesmo diapasão, sublinha a ausência de sentimento patriótico entre os protagonistas, o que justifica "o abandono da postura nacionalista em literatura ou em outra manifestação artística” (p. 253)

7 O projeto Amores Expressos elegeu dezesseis escritores brasileiros que viajariam, por um mês, para dezesseis cidades estrangeiras diferentes, a exceção de São Paulo, com a incumbência de escrever uma narrativa em torno do tema "amor", como também elaborar um blog. O projeto gerou outros produtos midiáticos, como a série de documentários para a TV, com a direção de Tadeu Jungle e Estela Renner, e exibido, em 2011, pela TV Cultura. Há cerca de 75.300 entradas na Internet sobre o Projeto, seus produtos e derivados. 
Frente a esse estado de coisas e àqueles paradigmas epistemológicos mencionados por Santiago, talvez não seja ocioso indagar se seria sintomática, hoje, a retomada de textos que interpretam a formação do Brasil, considerando a Nação como uma "comunidade imaginada" (ANDERSON, 2008), vista como uma totalidade. Que significa a volta aos textos clássicos e canônicos, num momento em que a nação vai deixando de ser o centro de um sistema de significação? Enfraquece a "fome de Brasil", como sublinha Alvaro Costa e Silva, na matéria publicada no Prosa \& Verso, de O Globo (9/08/2014), quando discorre sobre o relançamento da obra romanesca de Antonio Callado, pela José Olympio? Quando essa fome está saciada, ou a nação não atrai mais o apetite de pensadores e ficcionistas, voltar a essa tradição parece ser uma estratégia recorrente. Quando a nação se torna um problema, uma questão, mesmo uma ausência, um espectro (como mostrei no ensaio "Imaginar a nação em tempo heterogêneo: herança, espectro, resíduos", GOMES, 2014), a tradição que fala da formação do país é revisitada, posta em circulação. Estão aí as antologias, as reedições e releituras, bem como as participações sucessivas em congressos (BRASA, APSA) de nosso grupo Intérpretes do Brasil, coordenado por Luiz Fernando Valente, da Brown University. É ainda curioso constatar as 727.000 entradas de Intérpretes do Brasil na Internet, sites com biografias e textos dos intérpretes canônicos, sites denominados exatamente "Intérpretes do Brasil".

Neste sentido, vale lembrar o livro de Fernando Henrique Cardoso, Pensadores que inventaram o Brasil (2013) e a coletânea Intérpretes do Brasil: clássicos, rebeldes e renegados, organizada por Luís Bernardo Pericás e Lincoln Secco (2014), que, como afirma Francisco Carlos Teixeira da Silva (2014), ao reabilitar pensadores heterodoxos ao lado de clássicos, figurinhas carimbadas de toda a seleção dos intérpretes do Brasil, a coletânea abre debate sobre outros nomes que recebem pouca atenção da academia, a exemplo de Astrojildo Pereira, Rui Facó, Leôncio Basbaum, entre outros rebeldes e renegados. ${ }^{8}$

O livro de ensaios do ex-presidente do Brasil reúne dezoito textos, em que dialoga com seus mestres sobre os temas recorrentes que unificam o volume: o embate entre Estado e sociedade civil, o legado da colonização, as vicissitudes da democracia, os entraves ao desenvolvimento econômico, a promoção da justiça social. Mas além da análise dos textos, o ex-presidente contextualiza obras e autores, muitas vezes tratando do impacto pessoal que os últimos lhe causaram. De fato, em alguns casos, se trata de afinidades não somente intelectuais: por circunstâncias geracionais e entrecruzamento de vida, FHC se beneficiou do contato direto com vários dos autores cujas obras comenta no livro, em suas tentativas clássicas de explicação do Brasil - como ressalta o site da Companhia das Letras, que publicou o volume. ${ }^{9}$

8 Uma panorâmica do livro pode ser visualizada pelo sumário, indicando em negrito o nome dos pensadores, intérpretes do Brasil analisados em cada ensaio, seguidos dos nomes de quem os assina Assim temos uma idéia geral do volume: Octávio Brandão, João Quartim de Moraes | Heitor Ferreira Lima, Marcos Del Roio | Astrojildo Pereira, Antonio Carlos Mazzeo | Leôncio Basbaum, Angélica Lovatto | Nelson Werneck Sodré, Paulo Ribeiro da Cunha | Ignácio Rangel, Ricardo Bielschowsky | Rui Facó, Milton Pinheiro | Everardo Dias, Marcelo Ridenti | Sérgio Buarque de Holanda, Thiago Lima Nicodemo | Gilberto Freyre, Mario Helio Gomes de Lima | Câmara Cascudo, Marcos Silva | José Honório Rodrigues, Paulo Alves Junior | Caio Prado Júnior, Luiz Bernardo Pericás e Maria Célia Wider | Edgard Carone, Marisa Midori Deaecto e Lincoln Secco | Florestan Fernandes, Haroldo Ceravolo Sereza | Ruy Mauro Marini, Guillermo Almeyra | Jacob Gorender, Mário Maestri | Antonio Candido, Flávio Aguiar | Celso Furtado, Carlos Mallorquín | Rômulo Almeida, Alexandre de Freitas Barbosa | Darcy Ribeiro, Agnaldo dos Santos e Isa Grinspum Ferraz | Mário Pedrosa, Everaldo de Oliveira Andrade | Maurício Tragtenberg, Paulo Douglas Barsotti | Paulo Freire, Ângela Antunes | Milton Santos, Fabio Betioli Contel.

9 Cf. http://www.companhiadasletras.com.br/detalhe.php?codigo=13540. 
Ao lado da recorrência a essa tradição, observam-se deslocamentos para outros objetos como fotos, artes plásticas, artes visuais, artes performáticas, obras de multimídias, narrativas migrantes (FIGUEIREDO. 2012). A eles se junta o livro organizado por André Botelho e Lilian Schwarcz, Agenda brasileira: temas de uma sociedade em mudança (2011), com dezessete textos sobre temas dos mais diversos, escritos por professores e pensadores de várias universidades brasileiras. A idéia que circula nos ensaios não é mais a formação do Brasil, mas um levantamento do estado de coisas de um país em mudança, que constitui de fato uma "agenda", no seu sentido etimológico de "coisas que devem ser feitas", do gerundivo do verbo latino agere, fazer. Como dizem os organizadores na introdução "Um país de muitas faces", o livro busca responder à pergunta: "Como pensar os principais temas do país a partir de uma perspectiva atual? Quais os novos desafios e como reavaliar velhas questões sociais olhando firme o século XXI?" E complementam: “A idéia não é seguir intelectuais, mas antes temas da nossa agenda nacional; não tanto as teorias, mas as práticas, assuntos e questões que vêm contribuindo para desenhar projetos de nacionalidade, intencionais ou não" (p. 11). Na palavra "agenda" está inscrito o traço semântico de futuro. Os verbetes, aqui, mesmo em sua forma sintética, não abrem mão do solo histórico, para contextualizar o presente, reelaborar uma herança, a nossa formação, para abrir a agenda de inserção, conceito que circula em vários textos: "afirmação do presente como instância temporal a ser conquistada e vivida", como sublinha Luiz Camillo Osório, no ensaio "Arte contemporânea brasileira: multiplicidade poética e inserção internacional" (p. 59), em que se percebe o deslocamento do paradigma de "formação" para o de "inserção", semelhante ao que vem trabalhando Silviano Santiago (2013, p.259-266)

Talvez possamos considerar a hipótese de que esse modelo de visão totalizante, que vem da tradição romântico-modernista (ver o projeto de José de Alencar, no prefácio "Bênção paterna", de Sonhos d'ouro (1872), bem como os projetos e a correspondência de Mário de Andrade) e que implica uma metodologia e suas conotações ideológicas, perde sua potência, relacionado à crise dos grandes paradigmas da modernidade, das grandes narrativas (Lyotard, 2006), perspectiva que se projetava no paradigma de formação e buscava interpretar o Brasil como uma unidade feita de diversidades. Resíduos dessa proposta podem ser vistos em alguns produtos midiáticos como o Projeto Quadrante, coordenado por Luiz Fernando Carvalho para a Rede Globo de Televisão.

Se tal modelo de totalizar o Brasil resiste, por outro lado vai cedendo lugar às pequenas narrativas, interpretações parciais, que consideram o banal, o cotidiano urbano, as subjetividades, os anônimos (ver, neste sentido, os contos de Anônimos, de Silviano Santiago, 2008, ou os fragmentos de eles eram muitos cavalos, de Luiz Ruffato, 2001), recortes parciais inseridos no contexto da globalização, em que o tempo da nação é um tempo desigual, heterogêneo, que responde às diferentes experiências dos distintos grupos sociais, como argumentou Partha Chaterjee (2008), ao criticar a formulação de Benedict Anderson sobre a nação como comunidade imaginada, num tempo homogêneo e vazio. A radicalidade da crítica do professor indiano aposta no resgate da potencialidade do fragmento ante a intenção universalista ou idealista do discurso ocidental sobre os nacionalismos (Vichi, 2008, p. 11), ao indagar quem e como se imagina a nação, fora dos universais da tradição do pensamento eurocêntrico.

Resíduos da tradição romântico-modernista podem ser observados no Projeto Quadrante que resgata o parâmetro da totalidade. Como mostrei no ensaio "Uma série brasileira de televisão: uma alegoria nacional?" (2009), sobre Hoje é dia de Maria, outra produção dirigida por Carvalho, a Rede Globo também procura de alguma forma assegurar a integração 
nacional: "Ali também se plasmaria a identidade cultural do Brasil, afinal 'a gente se vê por aqui', diz um dos bordões da emissora." Algumas telenovelas e minisséries desempenham hoje um papel decisivo na constituição do imaginário social, semelhante ao folhetim do século XIX e do romance.

Destaca-se, nesse sentido o Projeto Quadrante. Iniciado em junho de 2007, busca adaptar/recriar para a televisão obras da literatura brasileira como $A$ pedra do reino, de Ariano Suassuna (jan. 2007), Capitu, versão do romance D. Casmurro, de Machado de Assis (dez. 2008), e a anunciada adaptação do romance Dois irmãos, do amazonense Milton Hatoum (a ser exibida em 2015), bem como de Dançar tango em Porto Alegre, do gaúcho Sérgio Faraco, perfazendo assim os quatro quadrantes do Brasil, como se vê graficamente no logotipo do projeto na página da Globo na Internet (www.quadrante.globo.com): um círculo fechado a sugerir uma totalidade, formado pelos quadrantes, com um ponteiro no centro que se move como o de uma bússola, indicando os pontos cardeais, que marca o espaço-tempo de um Brasil, cada um representado por uma obra literária que migra para outra mídia, que, juntas, constituem uma totalidade feita de diversidades.

Recortar aspectos mais particulares e locais, evitando transformá-los em peças de uma alegoria nacional, vem se revelando uma estratégia da literatura e da cultura das mídias para dar conta de fragmentos do Brasil, singulares ocorrências, quase sempre do universo cotidiano urbano, enveredando por uma estratégia de reterritorialização. Esta tendência no meio da multiplicidade de temas, linguagens, formatos e suportes, que caracteriza a produção cultural brasileira da contemporaneidade (RESENDE, 2006; SCHOLLHAMMER, 2010), permite reciclar o paradigma que envolve herança (em suas várias acepções) e resíduos, para, de certa forma, oferecer interpretações parciais do Brasil. Recicla-se, num processo de intertextualidades, modos ou jeitos do Brasil, o que está ao redor da nação, enquanto uma "casa assassinada". Reciclam-se e ressemantizam-se traços de nossa formação que permanecem em outro tempo, observando e absorvendo a superposição de temporalidades distintas, para reler a permanência e a mudança de uma tradição com seus aspectos arcaicos e modernos. Tempo heterogêneo que supõe um público também heterogêneo, o que implica a relação entre estética e política, na acepção que lhe dá Jacques Rancière (2009), concebendo o trabalho político do artista como investigação de determinado aspecto da realidade que está enquadrado, estereotipado ou formatado pelo senso comum, restituindo a força da experiência, da palavra, das imagens, para reconfigurar o mundo sensível.

É o caso do filme $O$ som ao redor, de Kleber Mendonça Filho (2012). Localizado num bairro de classe média alta do Recife, radiografa a questão urbana contemporânea, buscando suas raízes na nossa cultura escravocrata e na cultura do medo, também ela uma herança histórica. "A ligação entre a aflição presente e a herança passada se anuncia já no prelúdio à ação do filme, uma sequência de fotografias em preto e branco de engenhos de açúcar no interior de Pernambuco" (MENA, 2013, p. 5). O engenho e a rua moderna do Recife se sobrepõem, numa espécie de crônica fragmentada do cotidiano, em que subjazem conflitos de toda ordem: sociais, culturais, de gênero, raciais, de classe, de autoritarismo. A oligarquia só muda de endereço. A herança vem tanto das narrativas do ciclo da cana-de-açúcar, a exemplo, de Fogo morto, de Lins do Rego, como de Gilberto Freire e de Sérgio Buarque. A idéia de "formação" aqui é contaminada, centrifugada, pela questão urbana, também ela herdeira daquela formação.

Como atesta Ismail Xavier, evocando Sérgio Buarque de Holanda, de Raízes do Brasil: "Tudo se resolve no plano das relações pessoais, de poder, mando e serventia, fora da noção abstrata de cidadania e fora da ordem institucional democrática. È a sobrevivência 
de certas tradições que a modernização não dissolve" (apud MENA, p. 5). Essas raízes do Brasil ainda estão aí, ainda emperrando a realização de nossa modernização, que continua incompleta. Os sons ao redor do passado e do presente se misturam no contemporâneo e passam a ser "um detonador de ações do roteiro". (MENA. p. 5). O som que incomoda os personagens e o espectador potencializa as tensões, retratadas em situações corriqueiras do cotidiano urbano, no mundo privado da casa e no mundo público da rua monitorada pela milícia não-estatal que se instaura no bairro, a pretexto de segurança numa ordem policial. Percebe-se que o assunto é o Brasil, a nação como espectro, que se move entre resíduos arcaicos e arquitetura e urbanismo (pós)modernos, revelando a multiplicidade temporal que nos caracteriza. Sintomático nesse sentido, é o contraste entre as atividades do cotidiano banal da cidade e a visita às ruínas do velho engenho, que está de fogo morto, evocando, entretanto, as tensões entre a casa grande e a senzala, que, por sua vez, são redimensionadas no ambiente urbano do Recife de hoje. O filme de Kleber Mendonça Filho parece ser uma resposta possível para a questão: como representar, ou imaginar, a nação em tempo heterogêneo?

Narrativas deste naipe dialogam com a tradição de interpretar o Brasil e revelam como a Nação pode ser imaginada de outras maneiras, em diferentes formas de configurá-la. O que implica a busca de novos modos de interpretá-la. Rentáveis, nesse sentido, são as conexões e os paradoxos que marcaram os processos de constituição de nossa identidade nacional. Tais textos ficcionais e midiáticos tornam nossos contemporâneos os modernistas e seus modos de usar a nação (pedagogicamente interpretam o Brasil), e apontam como vêm se dramatizando os impasses da concepção de nação legada pela tradição que a narrativa pós-moderna reelabora, performativamente, sobretudo em suas representações do urbano. Estratégias de leitura talvez consistam em abordar as narrativas brasileiras contemporâneas, ultrapassando as fronteiras disciplinares ou discursivas em suas especificidades, promovendo o diálogo entre reflexão crítica e produção artística e midiática. E apontar para os sistemas culturais nacionais e transnacionais, espaços fronteiriços como processos contraditórios que permitem redimensionamento de tradições. Entre elas, os modos de usar a nação, mesmo enquanto residual ${ }^{10}$ de uma passagem que não existe mais, mas deixam rastros, vestígios e memórias, estoque de narrativas, imagens, metáforas, que formam um acervo a ser saqueado e redimensionado em outro tempo. Heranças, leite derramado, órfãos do Eldorado, títulos de ficções de Silviano Santiago (2008), Chico Buarque (2010) e Milton Hatoum (2008), respectivamente, podem ser lidos como metáforas, que conotam perda, orfandade (que os filmes de Walter Salles Jr. dramatizam), esterilidade, inutilidade, vazio, ausência, no entanto tais narrativas tratam do que ainda resta enquanto resíduos de uma utopia em ruínas, das raízes europeizadas, e por outro lado, arcaizantes, de ruídos que atravessam janelas e incomodam o presente, onde reverberam ecos do passado, apa-

10 A noção de residual, segundo Raymond Williams (1979), compreende as formações culturais surgidas no passado atuando no sujeito, dando sentido às nossas existências, pois são formações de que somos feitos: nossa história familiar e cultural, nossa memória. Tais resíduos podem ser flagrados em práticas subjetivas e culturais. Um processo cultural, por apresentar determinadas características dominantes em uma época específica, é tomado como o sistema cultural, com a pretensão de equivaler a uma totalidade. No entanto, numa análise histórica, para se dar conta de fato da totalidade do processo cultural, torna-se inevitável compreender as diversas temporalidades (marcadas pelo "residual", pelo "dominante" e o "emergente") e as interrelações entre movimentos e tendências dentro da cultura dominante. Para Williams, enquanto o emergente diz respeito à criação contínua de "novos significados e valores, novas práticas, novas relações e tipos de relação", apontando para o futuro, o "residual", por definição, foi efetivamente formado no passado, mas ainda está ativo no processo cultural, não só como elemento do passado, mas como elemento efetivo do presente" (1979, p. 125). 


\section{Conexão Letras}

rentemente morto, mas são espectrais e como tal têm uma sobrevida. Ao reelaborar essas heranças, essas narrativas literárias ou midiáticas, ou os ensaios das ciências sociais, podem ajudar a decifrar o Brasil, mesmo que sejam respostas provisórias, que se inscrevem nas engrenagens do tempo, desconstruindo os princípios de coesão e unidade.

\section{Referências}

ANDERSON, Benedict. Comunidades imaginadas: reflexões sobre a origem e a difusão do nacionalismo. São Paulo: Companhia das Letras, 2008.

BARRETO, Lima. O triste fim de Policarpo Quaresma. São Paulo: Penguin \& Companhia das Letras, 2013.

BOTELHO, André; SCHWARZ, Lilia Moritz. Intodução - Um país de muitas faces. In: _. (Org.). Agenda brasileira: temas de uma sociedade em mudança. São Paulo: Companhia das Letras, 2011.

BUARQUE, Chico. Leite derramado. São Paulo: Companhia das Letras, 2010. CARDOSO, Fernando Henrique. Pensadores que inventaram o Brasil. São Paulo: Companhia das Letras, 2013.

CARVALHO, Bernardo. O filho da mãe. São Paulo: Companhia das Letras, 2009. CARVALHO, José Murilo de. 500 anos de ilusão. Caderno Mais. Folha de São Paulo, 08 de agosto de 1999.

CELSO, Conde de Affonso. Por que me ufano de meu pays. 4. ed. Paris: Garnier, s.d. CHATERJEE, Partha. La nación en tiempo heterogéneo y otros estudios subalternos. Buenos Aires: Siglo XXI, 2008.

CUNHA, Eneida Leal . Do crânio da onça jabuti faz seu escudo: Silviano Santiago como intérprete do Brasil. Letterature d'America, v. 135, p. 67-78, 2011.

FIGUEIREDO, Vera Lucia Follain de. Em busca da Terra Prometida: o cinema reinventando a nação. In: Narrativas migrantes: literatura, roteiro e cinema. Rio de Janeiro: PUC-Rio; 7Letras, 2010.

GOMES, Renato Cordeiro. Heranças, espectros, resíduos: imaginar a nação em tempos heterogêneos. In: RESENDE, Beatriz; FINAZZI-AGRÒ, Ettore (Org.). Possibilidades da nova escrita literária no Brasil. Rio de Janeiro: Revan, 2014.

GOMES, Renato Cordeiro. Uma série brasileira de televisão: uma alegoria nacional? Matrizes culturais e formatos industriais. In: SOUZA, Eneida Maria de; MARQUES, Reinaldo (Org). Modernidades alternativas na América Latina. Belo Horizonte: UFMG, 2009.

HATOUM, Milton. Órfãos do Eldorado. São Paulo: Companhia das Letras, 2008. HOLANDA, Sérgio Buarque de. Visão do Paraíso: os motivos edênicos no descobrimento e colonização do Brasil. São Paulo: Companhia das Letras, 2010. LYOTARD, Jean-François. A condição pós-moderna. 6. ed. Rio de Janeiro: José Olympio, 2006.

MENA, Fernanda. O som e o sentido: no quintal de Kleber Mendonça Filho, Ilustríssima. Folha de S. Paulo, 17 fev. 2013.

MIRANDA, Wander Melo. Nações literárias. Cotia: Ateliê, 2010.

OSÓRIO, Luiz Camillo. Arte contemporânea brasileira: multiplicidade poética e inserção internacional. In: BOTELHO, André; SCHWARZ, Lilia Moritz (Org.). Agenda brasileira: temas de uma sociedade em mudança. São Paulo: Companhia das Letras, 2011. 
RANCIÈRE, Jacques. A partilha do sensível: estética e política. São Paulo: Ed. 34, 2009.

RESENDE, Beatriz. Contemporâneos: expressões da literatura brasileira no século XXI. Rio de Janeiro: Casa da Palavra, 2006.

RUFFATO, Luiz. eles eram muitos cavalos. São Paulo: Boitempo, 2001.

SANTIAGO, Silviano (Org.). Intérpretes do Brasil. Rio de Janeiro: Nova Aguilar, 2000. $3 \mathrm{v}$.

SANTIAGO, Silviano. Anônimos. Rio de Janeiro: Rocco, 2008.

SANTIAGO, Silviano. Formação e inserção. In: Aos sábados, pela manhã: sobre autores e livros. Rio de Janeiro: Rocco, 2013.

SANTIAGO, Silviano. Formação e inserção. Sabático. Estado de S. Paulo, 26 maio 2012.

SANTIAGO, Silviano. Heranças. Rio de Janeiro: Rocco, 2008.

SANTIAGO, Silviano. Mário, Oswald e Carlos, intérpretres do Brasil. Alceu. Rio de Janeiro, 2005, vol. 5, n. 10, p. 5-17.

SCHOLLHAMMER, Karl Eric. Ficção brasileira contemporânea. Rio de Janeiro:

Civilização Brasileira, 2010.

SECCO, Lincoln; PERICÁS, Luís Bernardo (Org.). Intérpretes do Brasil: clássicos, rebeldes e renegados. São Paulo: Boitempo, 2014.

SILVA, Francisco Carlos Teixeira da. O retorno de intérpretes esquecidos do Brasil. Prosa \& Verso, 08/03/2014. http://oglobo.globo.com/blogs/prosa/posts/2014/03/08/oretorno-de-interpretes-esquecidos-do-brasil-526893.asp. Acesso 29 jun. 2014.

SOUZA, Eneida Maria de. Espelho de tinta. In: Janelas indiscretas: ensaios de crítica biográfica. Belo Horizonte: Ed. UFMG, 2011.

SQUEFF, Enio. Ariano Suassuna e os intérpretes do Brasil. JáEditora. http://jornalja. com.br/2014/07/28/ariano-suassuna-e-os-interpretes-do-brasil. Acesso em 15 set. 2014.

SUASSUNA, Adriano. Leia frases de Adriano Suassuna. http://oglobo.globo.com/ cultura/livros/leia-frases-de-ariano-suassuna-13357628. Acesso em 15 ago. 2014.

VICHI, Víctor. Presentación. In: CHATERJEE, Partha. La nación en tiempo heterogénio y otros estudios subalternos. Buenos Aires: Siglo XXI, 2008.

WILLIAMS, Raymond. Marxismo e literatura. Rio de Janeiro: Zahar, 1979.

REFERÊNCIA FILMOGRÁFICA

O som ao redor. Direção Kleber Mendonça Filho. Produção Emilie Lesclaux. 2012. 